\title{
Mosquito-Borne Diseases, Pesticides Used for Mosquito Control, and Development of Resistance to Insecticides
}

\author{
Jaime A. Cuervo-Parra, Teresa Romero Cortés and Mario Ramirez-Lepe \\ Additional information is available at the end of the chapter \\ http://dx.doi.org/10.5772/61510
}

\begin{abstract}
Mosquitoes are one of the most dangerous insects in the world for humanity. Over one million people worldwide die from mosquito-borne diseases every year. Mosquito vectored diseases include protozoan diseases, i.e., malaria, filarial diseases such as dog heartworm, and viral diseases such as dengue, encephalitis, and yellow fever. In addition, mosquitoes transmit several diseases and parasites that dogs and horses are very susceptible too. These include dog heartworm, West Nile virus (WNV), and eastern equine encephalitis (EEE). Since its discovery, chemical insecticides have represented the most widely method used to control mosquito-borne vectors. However, the effects of chemical insecticides on mosquito vector populations are usually transitory because vectors can rapidly develop resistance against them. Each insecticide triggers the selection of one or more mechanisms of resistance. These mechanisms include changes in the target site of action and metabolic detoxification among others.
\end{abstract}

Keywords: Mosquito, resistance, insecticide, pesticide, vector, disease

\section{Introduction}

Mosquito-borne vectors are responsible for the transmission of various causative agents of infectious diseases that can be lethal for humans. During the last decades, several diseases have increased incidence and expanded into new geographical areas. Among the factors that can favor the spread of disease are the increase of population density, the increase of international travel, and the increase of the import and export of goods at international level [1]. The number of recent notifications of mosquito-borne diseases in the world is a matter of concern, and currently there are no effective vaccines available against most of these diseases. In many parts of the world, mosquito presence is a problem because each season presents different species that are vectors of diseases with medical and animal importance because they feed from man 
and other organisms. Therefore, the only way to avoid epidemics of mosquito-borne diseases is through the control of insect vectors and through knowledge of its biology, behavior, and environmental factors that facilitate its transmission [2].

Mosquitoes' vector characteristics vary depending on the particular conditions of their habitat of origin. During its life cycle, mosquito goes through four stages, which are egg, larva, pup, and adult, of which the first three stages need stagnant water to develop. Generally, adult mosquitoes are small insects, fragile, with slender bodies, a pair of narrow wings and three pairs of long slender legs. They vary in length from 3.16 to 1.2 inch (5 to $13 \mathrm{~mm}$ ). They are equipped with an elongated proboscis with mouthparts adapted for piercing skin, which the female uses for snacks and to feed on blood.

Over the last decades, the struggle of pests has been based on the large-scale use of chemical pesticides, as well as the elimination of all containers, artificial or natural, which can be given favorable conditions for the development of the prolific mosquito breeding sites [3]. However, the negative effects of chemicals on nontarget organism populations and the resistance development to these chemicals in mosquitoes, along with the resent resurgence of different diseases transmitted by mosquitoes, have led to search other alternative methods, more simple and sustainable for mosquito control.

\section{Mosquito-borne diseases}

With the recent expansion of Aedes albopictus, there are epidemiological reports for several mosquito-borne diseases occurred in various parts of Europe [4]. These evidences show that the problem does not constitute an exclusive problem of tropical, subtropical, and/or developing countries. In North America, several mosquito vectors species of the Culex, Anopheles, and Aedes genera that transmit several diseases to humans are present [5]. Meanwhile, in Central and South America, the main disease in humans transmitted by mosquito vectors of the Anopheles, Aedes, Culex, and Ocherotatus genera are malaria, dengue, yellow fever, filariasis, St. Louis encephalitis, and western equine encephalitis [6].

Mosquito-borne diseases occur when the specific biological agent that causes the disease is transmitted to human hosts through a nonhuman carrier called vector. Therefore, the chain of transmission involves three factors: one host, usually a human, an invertebrate vector responsible for spreading the disease, and the biological agent that may be a virus, bacterium, or parasite. Vectors may act biologically or mechanically, where the mechanical vectors only transport the pathogenic agent; however, in biological vectors, agent develops and multiplies before becoming infective to the vertebrate host [7]. In that context, mosquito-borne diseases of public health importance are complex, and its occurrence will depend on the interaction of various factors such as biological, ecological, social, and economic factors [8].

\subsection{Malaria}

Malaria or paludism is caused by parasites of genus Plasmodium, which is transmitted to humans by the bite of female Anopheles mosquitoes. Plasmodium falciporum is responsible for 
most severe cases, usually causing coma or anemia in patients, which flows into death. Meanwhile, Plasmodium vivax causes recurring fevers and lesions in the brain and liver, but it rarely causes death [9]. Within the measures applied to control, Anopheles vectors, for a long time, was based on the application of DDT (1,1,1-trichloro-2,2-bis [Q-chorophenyl] ethane), but currently it is beginning to use pyrethroids in outbreaks and transmission foci [10].

While the disease appeared to be under control in the 1950s, the infection again reappeared in many countries due to the resistance generated by vectors to insecticides of plasmodia and chloroquine. This disease is responsible for the deaths of between 700,000 and 2.7 million people [11]. Moreover, malaria causes between 400 and 900 million cases of acute fever per year in children fewer than five years in these areas. Therefore, malaria is the disease with the highest prevalence in areas with limited economic resources, causing the largest number of cases in the warm and rainy seasons. The solution to eradicate this disease would be the application of vaccine [12].

\subsection{Yellow fever}

This disease is caused by the yellow fever virus, an arbovirus, belonging to the Flavivirus genus is present in tropical areas of Africa and South America. Aedes aegypti mosquito is the most important vector in the transmission of the yellow fever disease in America [13]. Yellow fever virus infects both humans and monkeys, being monkeys the main reservoir of infection and transmission from monkey to monkey in woodlands and jungle. Haemagogus jantinomys and Sabethes choropterus mosquitoes are the vectors responsible for the transovarially virus transmission among the primate species [14]. On the other hand, the infection is transmitted to humans through A. aegypti mosquito bites. Yellow fever virus causes 200,000 clinical cases of disease and 30,000 deaths each year, of which $90 \%$ of the cases correspond to the African continent [15]. Unfortunately, the most of the cases and deaths are not recognized because it occurs in rural areas where surveillance and reporting are inadequate. Yellow fever distribution in America ranged from Philadelphia, in the United States, until the line connecting Bahía Blanca and Mendoza in Argentina. On the other hand, in Africa, it is located in the sub-Saharan Africa [16]. This disease can be fatal and acute or mild and inapparent. Because there is no specific antiviral treatment against it, the best strategy to prevent its spread is the prevention of infection [17]. In this context, vaccination is the best preventive measure against yellow fever.

\subsection{Dengue}

Dengue is a viral disease caused by infection of four viruses, known as dengue 1, 2, 3, and 4, which is endemic in more than 100 countries in Africa, America, the Eastern Mediterranean, Southeast Asia, and the Western Pacific, the latter two being the most severely affected. These viruses belong to the genus Flavivirus, Flaviciridae family. The most important mosquito vector is A. aegypti and to a lesser degree A. albopictus. Once an infected mosquito bites a human, the virus goes through an incubation period of between 3 and 14 days before disease symptoms appear. Furthermore, passive dispersion through means of transport is one of the most 
important factors that favor the spread of these mosquitoes and dengue virus from one region to another.

This disease is of major interest to public health because of its great impact on morbidity and mortality in the world since it is the viral disease transmitted by mosquito vectors most common and important worldwide [18]. The World Health Organization estimated that there may be 50 to 100 million dengue infections, a half-million hospitalizations, and 22,000 deaths worldwide every year [19]. Moreover, because of the absence of a vaccine to protect the population at risk, vector control is the most important method for the prevention and interruption of the transmission of the disease. The use of chemical insecticides is a key component in the control of larvae and adult mosquito vector populations. However, derived from overuse for over five decades of these insecticides to interrupt the transmission of the virus, it has generated resistance to different molecules of insecticides by part of mosquito vectors [19].

\subsection{Venezuelan equine encephalitis}

This disease is caused by the Venezuelan equine encephalitis virus (VEE) or encephalomyelitis in horses, donkeys, zebras, and humans. VEE virus cause acute infections in vertebrates characterized by the presence of high viremia and disease development with varying degrees of severity. Once the equines get the disease, they may die suddenly or present progressive disorders of the central nervous system. Furthermore, in humans, it causes mild to severe influenza-like symptoms, with fever and headache. Around $4-14 \%$ of cases develop neurological complications and near $1 \%$ of reported cases die [20].

The VEE complex contains a number of virus, belonging to the Alphavirus genus of the Togaviridae family, which have been classified into six viral subtypes, ranging from I to VI. VEE virus are present in all continents and most often are transmitted by the bite of infected Culex (C. vomerifer, C. pedroi, C. adamesi) and Aedes (A. taeniorhynchus) mosquito vectors and can also be transmitted through aerosols [21]. Although virtually any mosquito can be found infected with VEE virus during epizootics, it is thought that $A$. taeniorhynchus is the main vector responsible for transmitting VEE virus during outbreaks, whereas Culex mosquitoes species transmitted enzootic virus strains of VEE [22]. Subcutaneous injection, nasal instillation, and contact with broken skin or bedding contaminated animals are other ways to spread the virus, especially in a lab environment [23].

Epizootic and enzootic strains of VEE virus spread from northern Argentina to Florida and parts of the Rocky Mountains, being more frequent in northern South America. Since 1930, there have been 21 outbreaks of VEE throughout the American continent, being considered an emerging disease naturally due to mutations of the enzootic and endemic virus strains that circulate as a vector-borne disease among mammals host populations, especially in habitats such as forests and wetlands [24]. Some of the strategies used to reduce outbreaks of VEE in horses are through the implementation of the TC- 83 vaccine and by protecting against mosquitoes by wearing protective clothing and/or insecticides. Although, the TC- 83 vaccine is used in laboratories, there is still no licensed vaccine available to humans for the prevention of infection by the epizootic strains of VEE virus [25]. 


\subsection{Japanese encephalitis}

Japanese encephalitis (JE) is a viral disease transmitted to humans by mosquitoes of the Aedes and Culex genera, where main vectors are C. tritaeniorhynchus, C. annulus, C. annulirostris, $C$. vishnui, C. fuscocephala, and C. gelidus [26]. This disease affects horses, donkeys, pigs, and humans. Due to low qualifications and shorter duration of the viremia, humans or horses transmit the virus to other biting mosquitoes and are considered as terminal hosts [27]. The reservoirs of JE virus are pigs and wild birds. The incubation period is around 4-14 days. In pigs, JE causes reproductive losses (stillbirths and abortions), in horses, it causes encephalitis, and in humans, the disease can range from very serious to no symptoms. Neurologic sequelae occur in up to $80 \%$ of human cases and about 15,000 deaths annually [28].

JE is distributed across several areas of temperate and tropical Asia, with a higher incidence in rural areas of Southeast Asia, the Indian subcontinent and parts of Northern Asia. It also occurs, but less frequently in Japan, Taiwan, Singapore, Hong Kong, eastern Russia, and Australia [29]. Although the virus affects all age-groups, regions where there have been widespread childhood vaccination campaigns against the disease, the age distribution has changed, increasing the proportion of cases in older children and adults [27]. Therefore, the best alternative for control of JE it is the application of the vaccine, which is associated with the generation of neutralizing antibodies.

\subsection{Lymphatic filariasis}

Lymphatic filariasis, also know elephantiasis, is a parasitic disease caused by nematodes of the Filarioidea family, which is transmitted to humans by mosquitoes of the genus Anopheles, Culex, Aedes, and Mansonia, which inject various nematode larvae while feed on blood [30]. The disease is present in sub-Saharan Africa and Southeast Asia. It is a chronic parasitic disease in which adult worms lodge in the lymphatic vessels where they release microfilariae from the bloodstream. Filariasis can produce a wide variety of clinical manifestations whose symptoms include fever, lymphadenitis, and retrograde lymphangitis and thickening of the skin and underlying areas, caused by obstruction of the lymphatic system by the parasite. Although, the mortality associated with filariasis is low, the social and health consequences generated by their chronic manifestations are important because they cause severe disability in those subjects who suffer (blindness, deformities), which gives rise to a decrease in working capacity and in the economy [30]. Filariasis is classified as a neglected disease by the World Health Organization due to the limited investment by pharmaceutical companies for research into new treatments and the low professional interest on the part of health personnel in the countries of first world [31]. Against lymphatic filariasis, a combination of two drugs albendazole and ivermectin is used [32]

\subsection{Rift Valley fever}

The disease is caused by the Rift Valley fever virus, an RNA virus belonging to the Bunyaviridae genus of the Phlebovirus family. The Rift Valley fever (RVF) is a peracute or acute, febrile, mosquito-borne disease that causes fever of viral origin that affects domestic animals like cows, 
buffaloes, sheep, goats, camels, and humans [33]. The route of transmission of the disease commonly is associated with mosquito-borne epidemics during the rainy season. RVF has been isolated from more than 30 mosquito species, of which it is considered that the Aedes and Culex genera are the main disease vectors [34]. The presence of RVF virus has been detected in most countries of East, West, and Southern parts of the African continent, being the disease endemic in Southern and Eastern Africa, but also epidemics have been reported in Egypt, Saudi Arabia, and Yemen [35]. The high genetic diversity observed in the RVF virus in the East, West, and Southern Africa shows the ancestral origin of the disease for these regions. Further, since outbreaks found outside these African regions have limited genetic diversity, these outbreaks are the result of the introduction of a single strain of the virus from the center of Africa, followed by its spread by mosquitoes between the vulnerable animal and human population [36]. Most cases of this disease occur in veterinarians, slaughterhouse workers, laboratory personnel, and other employees who work directly with blood and tissues of animals. Therefore, an inactivated vaccine is available against this disease; nevertheless, it is only available to laboratory personnel and veterinarians not being yet available to general public.

\subsection{West Nile fever}

West Nile fever (WNF) is transmitted to humans through the bite of Culex and Aedes mosquitoes vectors of West Nile virus (WNV). This disease can affect birds, horses, and humans causing an unapparent infection, mild febrile illness, meningitis, encephalitis, an acute poliomyelitis-like syndrome, or death [37]. WNV is a member of the genus Flavivirus in the Flaviviridae family. This arbovirus is maintained in nature by cycling between several bird species and mosquitoes that support the WNV replication. The resulting symptoms of WNV is variable, and the disease does not cause obvious signs in some species but often kills them after suffering a fatal systemic disease in other species [38]. Among mammals, the cyclical disease occurs mainly in horses and humans. In horses, this disease is characterized by the presence of ataxia ranging from mild to severe, besides presenting weakness, muscle twitching, and cranial nerve deficits [39]. The mortality rate is about one in three clinically affected horses unvaccinated [40]. In humans, most infection cases are asymptomatic and are usually mild and flulike if symptoms occur. The development of severe disease characterized by neurological signs and appears to be rare in most outbreaks. However, since the 1990s, this situation changed since the WNV became an important human and veterinary pathogen. WNV has a broad geographic range that includes portions of Europe, Asia, Africa, Australia (Kunjin virus), and North, Central, and South America. The incubation period of this disease ranges from 3 to 14 days with severe symptoms, in one of every 150 people infected. Symptoms may last from a few days to several weeks and have reported that approximately $80 \%$ of infected people show no symptoms at all. Although all persons are able to acquire the WNV, people older than 50 years are at higher risk of developing more severe forms of the disease. Over the past decade, the understanding gained about the clinical spectrum of the disease as well as the short- or long-term associated with human WNV infection has been substantially increased. Presently, a vaccine is available only for horses, but not for humans.[41]. 


\subsection{Chikungunya fever}

Chikungunya fever is a viral disease, manifested by fever and severe arthralgia, prevalent in Africa, Asia, and Europe, and now emerging and little studied in the Americas and the Caribbean Islands since 2013 [42]. Chikungunya virus is transmitted to humans by Aedes vectors. There are two main vectors $A$. aegypti and $A$. albopictus, which are present in the tropics and temperate zones. Although $A$. aegypti has always been the main vector transmitter of the disease, in most recent outbreaks, A. albopictus has become the main vector. Chikungunya word comes from the makonde dialect spoken by an ethnic group of southeast Tanzania and northern Mozambique, which means the man who walks hunched over, due to the appearance shown by patients due to the severity of joint pain that they suffer [43].

The Chikungunya virus is an enveloped positive-strand RNA virus, belonging to the Alphavirus genus, group arbovirus $\mathrm{A}$, of the Togaviridae family. The virus affects all humans without distinction, being susceptible to contracting the disease individuals not previously infected with the virus, after individuals are infected, immunity is prolonged. Chikungunya fever epidemics spread rapidly within infected community until the development of immunity in the population affected stops transmission. In general, about $3-28 \%$ of infected people are asymptomatic, although they contribute to the spread of the disease. On the other hand, in the symptomatic forms, the clinical manifestations may be acute, subacute, or chronic. After the bite, the incubation period of the disease is 1-12 days characterized by fever, severe arthralgias, back pain, incapacitating myalgia, and conjunctivitis. Subsequently, after 2 or 3 days, maculopapular exanthem is described (sometimes only macular) in half of the cases, distributed on the trunk and extremities. Fever usually takes between 2 and 3 days, and leukopenia is the rule. Since there is no specific antiviral treatment or vaccine, treatment against the disease should be symptomatic against the symptoms presented by the patient and can be applied antipyretics, analgesics, anti-inflammatory, and ribavirin [44].

\subsection{St. Louis encephalitis}

St. Louis encephalitis (SLE) is a viral disease transmitted by mosquitoes of the Culex genus, where birds are the normal hosts of this disease that affects humans. Other potential vectors, which can become infected and transmit the SLE to vertebrate hosts, include the mosquito species of the Aedes, Mansonia, and Sabethes genera [45]. The SLE is a disease of greatest medical importance in North America prior the introduction of WNV in 1999. According to studies conducted in the United States, the sparrow has a key role in the chain of infection, and doves, blue jay, and robin are important too, being the young of these species most important that adults [6]. The SLEV may be enzootic in some places but eventually can occur epizootic in which a large number of birds become infected, also being able to cause infections in humans as isolated cases or epidemics, by the bite of mosquitoes infected with the virus. Under optimal conditions, the extrinsic incubation period of the virus is about 10 days, staying active throughout the life of the mosquito. Human infections with SLEV not always result in clinical manifestations of encephalitis, which is why it often goes unnoticed, except during epidemics [46]. The most susceptible population is of children and the elderly, and the mortality rate of SLE is between $5 \%$ and $20 \%$. Currently, SLE is widely distributed throughout American 
continent, from Canada, Mexico, Central and South America, and the Caribbean [6]. To date, a vaccine against SLE has not been developed [41] because antibiotics are not effective against this virus. Therefore, the best form of protection against the transmission of SLEV is to avoid mosquito bites as much as possible.

\subsection{Eastern equine encephalitis}

Eastern equine encephalitis (EEE) is caused by the eastern equine encephalitis virus (EEEV), an RNA virus classified in the family Togaviridae. EEE infections are characterized by symptoms such as fever, headache, nausea and vomiting, malaise and weakness, confusion, myalgia, arthralgia, and neck stiffness. The main vector species involved in outbreaks of disease are Coquillettidia perturbans, Culiseta melanura, Ochlerotatus canadensis, Aedes vexans, and Culex mosquito's species [47]. The cycle of transmission of EEE occurs between wild birds and mosquito vectors, and when mosquitoes bit humans they transmit the virus. Disease incubation period varies from 4 to 10 days, and the infection can result in one of two types of disease, systemic or encephalitis, depending on the age of the person and other host factors. The illness lasts one to two weeks, and recovery is complete when the central nervous system is not affected. In humans, the rate of mortality is around 3\%, and many of those recovering suffer some form of mental disability for life, and death usually occurs from 2 to 10 days after onset of symptoms. EEEV is found throughout the Western Hemisphere and North America in areas of the east of the Mississippi River in the US, southeastern Canada to Argentina, and Peru. The EEE was first recognized in humans in 1938 [48]. Since then, cases have been produced sporadically as small epidemics with a total of 223 reports between 1955 and 1993 [49], including a peak of 36 cases in 1959 [50]. Of this case, the third part of the patients affected died because of the disease. The diagnosis of the symptoms of EEE is difficult because the symptoms that occur in patients are nonspecific. Currently, the only available vaccine is for horses, and there is still no human vaccine for the general public.

\subsection{Western equine encephalitis}

The causal agent of Western equine encephalitis (WEE) is the WEE virus (WEEV), which is an arbovirus of the Togaviridae family, transmitted by mosquitoes of the Culex and Culiseta genres [51,52], of which Culex tarsalis is the main vector of WEEV in western North America [53]. The natural cycle of WEEV is maintained through alternating infection between birds and ornithophilic mosquitoes. WEE primarily affects birds, mosquitoes, humans, and horses. The clinical form of WEE occurs in humans and horses, which are dead-end hosts [54]. Clinical disease can result in febrile disease of variable severity associated with neurological symptoms that range from headache to aseptic meningitis or encephalitis. The WEE has been reported in the Western United States, Canada, Mexico, and Central and South America [54]. WEEV in humans results in mild disease in adults but can become serious encephalitis in children and elderly people. The mortality rate is between $5 \%$ and $15 \%$, of which about $50 \%$ of infants who survive have permanent brain damage. People can prevent WEE infection by avoiding outdoor activities at the primary feeding period of Culex and Culiseta mosquitoes or using mosquito repellents. For horses, a vaccine for WEE exists in the market, but there is no vaccine for humans [55]. 


\subsection{La Crosse encephalitis}

La Crosse encephalitis (LAC) is a disease caused by the La Crosse encephalitis virus (LACV). LACV is spread through the bite of infected mosquitoes of the Aedes genus, where A. triseriatus is the principal vector and reservoir of LACV in nature [56]. The vertebrate of the Sciuridae family are its normal hosts in forest habitats throughout the range of the disease [57]. Subsequently, the virus can be passed to humans by feeding on infected rodents with the virus, or transovarially from an infected female to offspring. LACV is distributed in the United States from the upper Midwestern states, primarily Illinois, Iowa, Indiana, Minnesota, Ohio, and Wisconsin to New York, and South to Texas, Alabama, and Georgia [58], with confirmed human cases of LAC in 29 of the lower 48 states [59]. The disease affects the central nervous system being able to become severe and fatal in rare cases [57]. After an incubation period of 5-15 days, LAC symptoms include fever, headache, nausea, vomiting, and fatigue and initially presents as a nonspecific summertime illness. Severe cases involving encephalitis occur more often in children under 16 years accompanied commonly of seizures and in some cases coma, paralysis, and long-term disability or death. There is no specific treatment against LACV infection, so care is based on symptoms. The best way to reduce the risk of becoming infected with LACV is to avoid mosquito bites, use insect repellents, wear clothes to avoid bites, or even stay indoors during peak hours of mosquito activity. Another preventive measure that provides good results is to eliminate mosquito breeding sites. There is no antiviral drugs or vaccine available against the LAC because antibiotics are not effective against viruses [57].

\subsection{Zika fever}

Zika fever (ZIKF) is caused by Zika virus (ZIKV), a flavivirus belonging to the family Flaviviridae. It is a disease of monkeys and humans spread through the bite of infected Aedes mosquito [60]. Where A. africanus and A. aegypti are the principal probable vectors [61]. Clinical symptoms are mild headache, maculopapular eruption in different parts of the body, transient fever, malaise, and joint pain. ZIKV is common in West and Central Africa but also occurs in Pakistan, India, Vietnam, Thailand, the Philippines, Malaysia, Indonesia and Micronesia. In 2014, the presence of ZIKV in some American regions was reported. There is no vaccine, drugs or specific treatment for ZIKF, so the strategies for prevention and control the disease include insect repellents and mosquito elimination [62].

\section{Mosquito control}

The prevention and control of mosquito-borne diseases globally is conducted through a comprehensive and thorough method of pest management. Where programs are not intended to completely eliminate mosquito populations but rather are aimed to reduce their number and therefore minimize the risk of disease transmission. Methods used to mosquito control include the elimination of breeding sites and the control of mosquito larvae and adults. Larvicides, by applying chemical insecticides in the breeding sites, are the best strategy to kill larvae and pupae of mosquitoes in the water. Larvicides are present in several forms ranging 
from powder, tablets, or liquids and include methoprene, monomolecular surface films, larvicidal oils, chemical insecticides, neurotoxic insecticides, plant-derived products, and larvicidal bacteria [19]. Adulticides technique is usually less efficient for mosquito control. However, it is the only way to kill adult mosquitoes and is the last line of defense in reducing mosquito populations. Some of the adulticide used for mosquito control include products derived from microorganisms, plants or minerals, synthetic molecules, organophosphates, some natural pyrethrins, or synthetic pyrethroids [63].

\subsection{Chemical insecticides}

Since its discovery, chemical insecticides have represented the most widely method used to control mosquito-borne vectors. However, the effects of chemical insecticides on mosquito vector populations are usually transitory because vectors can rapidly develop resistance against them. On the other hand, the environmental problems caused by the excessive use of chemical insecticides are a matter of current concern because it is estimated that about 2.5 million tons of pesticides are used annually, generating worldwide damage amounting to $\$ 100$ billion annually [64]. Some of the disadvantages that generates when using only chemical products are (a) the selection of new insecticide resistance in pest populations; (b) the resurgence of already treated populations; (c) the generation of waste, risks, and legal complications; (d) the destruction of beneficial species; and (e) the high costs in equipment, labor, and material. In addition, the highly toxic and nonbiodegradable properties of insecticides and waste generated in soil, water, food, and crops that affect public health are additional reasons to search new methods to help solve the problems caused by chemical insecticides [64]. Consequently, the concept of integrated control arises, a method in which pest and diseases control is performed using chemicals, useful organisms, and cultural practices.

The progress of science and the chemical industry in the nineteenth century, with the discovery of DDT, made possible the development and emergence of new conventional insecticides or so-called of synthesis [65]. The most used of these insecticides of synthesis are modulators of sodium channels (organochlorines, pyrethroids, and pyrethrins), acetylcholinesterase inhibitors (carbamates and organophosphates), and the chloride channel antagonists regulated by the gamma-aminobutyric acid or also known as GABA (organochlorine cyclodiene and phenylpyrazoles).

Using these conventional insecticides gave positive results against insects disease vectors at first. However, due to its massive use, insects soon began to develop resistance to them. Thus, an insecticide that initially was effective, just being useless in the long term. In response to this problem, new-generation insecticides also called biorational insecticides have been developed, whose research strategy is based on a good understanding of the physiological processes or mechanisms specific communication of insects, and in obtaining agents that are able to affect them. These products are divided into the following: those who are analogs of juvenile hormone and molting, inhibitors tissue formation, pheromones, insecticides that prevent hatching, and biological insecticides [66]. 


\subsubsection{Organophosphates and carbamates}

Organophosphate insecticides are phosphoric acid derivatives, having activity against a wide spectrum of invertebrate. It interferes with the action of enzymes called cholinesterases that regulate the neurotransmitter acetylcholine, resulting in first instance to muscle cramps, paralysis, and eventually death [67]. Therefore, these insecticides have a toxic action that blocks an enzyme acetylcholinesterase of central and peripheral nervous system of insects, in synaptic junctions. The enzyme rapidly hydrolyzed acetylcholine, resulting in the repolarization of the membrane or the basal plate in neuromuscular connections, preparing for the arrival of a new impulse. By forming strong covalent bonds between insecticide and acetylcholinesterase, the enzyme is inhibited, causing the accumulation of acetylcholine in the synaptic junction and the interruption of normal transmission of nerve impulses [68].

However, due to the generation of resistance in vector insects to these chemical products, the use of many of these organophosphate and carbamates insecticides is no longer effective. Furthermore, because cholinesterases and neurotransmitters acetylcholine also form part of vertebrate nervous system, organophosphate pesticides are highly or moderately toxic to vertebrates [69]. In this regard, temephos are the only organophosphate pesticide that is still used to control mosquito larvae. Although temephos are not persistent in the environment being that last 7-10 days [70], it has been shown in many studies the adverse effects of temephos on a wide range of no target aquatic taxa [71]. Furthermore, carbamate pesticides, just like organophosphates, act by inhibiting the cholinesterase enzyme. Therefore, the symptoms experienced by insects per carbamate poisoning are similar to those experienced with organophosphates. However, carbamate pesticides block acetylcholinesterase enzyme hydrolyzing acetylcholine in muscle by carbamylation, which is a reversible reaction [72]. Therefore, the recovery of carbamate poisoning in humans is faster than with organophosphate intoxication since the acetylcholinesterase enzyme is able to break apart of the carbamate [73].

\subsubsection{Organochlorines, pyrethroids, and pyrethrins}

Organochlorine insecticides are chlorinated hydrocarbons, which are known to be effective to control mosquito populations. Its mode of action is by inhibiting GABA receptor in the nervous system through the interruption of nerve impulses due to the closure of chloride channels [72]. Therefore, when an organochlorine binds to a GABA receptor, the receptor is unable to close GABA chloride channel, which results in stimulation of the nervous system and similar symptoms to poisoning with carbamates or organophosphates [74]. However, with the Stockholm Convention on Persistent Organic Pollutants, which entered into force on May 17, 2004, the use of 12 chemicals including DDT, aldrin, dieldrin, heptachlor, mirex, chlordecone, and chlordane was prohibited because of its long average life and toxicity [75]. However, an extension clause allows countries where malaria is endemic to use DDT to control vectors that transmit the disease. Taking into account the negative effects that DDT has for the environment, malaria programs without the use of insecticides have been developed with the assistance of the Pan American Health Organization [76].

On the other hand, pyrethroids and pyrethrins used to control mosquitoes break down faster in the sunlight as opposed to chemical or microbial breakdown. However, pyrethroids are 
considered axonic poisons, composed of more stable substances, or degrade slower in the presence of sunlight than pyrethrins and are generally effective against most of the insect pests of agriculture. Furthermore, pyrethroids can be combined with other active ingredients, such as piperonyl butoxide, to retard its degradation and prevents the insect's system from detoxifying the pyrethroid, making it more effective [72]. Delay that allows the chemical product persists longer in the environment, requiring smaller and less frequent doses to kill pests [77]. This type of insecticidal affects the central and peripheral nervous system of insects and have a rapid knock-down effect, by interfering with the sodium channels of nerve membrane causing the interruption of the transfer of ions and transmission of impulses between nerve cells [78]. Moreover, it stimulates nerve cells to produce repetitive discharges and eventually cause paralysis and death [79]. Furthermore, because pyrethroids act on the nervous system of insects through a different pathway from the organophosphate pesticides, they generally have low toxicity in mammals and birds; however, they are toxic to fish and tadpoles [80].

\subsubsection{Biorational insecticides}

Biorational insecticides are those that have relatively low toxicity to humans and have few environmental effects. Among which, methoprene is an insect growth regulator insecticide with a broad spectrum of action that interferes with the insect life cycle preventing maturity or reproductive stage [81]. Meanwhile, the juvenile hormone analogue is a biorational insecticide that causes deformations in larval stage, death in the pupal stage, and sterility effect in adults [82]. Spinosad is another biorational insecticide that comes from a Saccharopolyspora spinosa neurotoxin, made by a mixture of spinosyns A and D. Spinosad act on the postsynaptic nicotinic acetylcholine receptors and GABA receptors and has proven its usefulness in the dipterans control [83]. Pyriproxyfene is another new-generation insecticide that has been tested in adult and larval mosquitoes causing a reduction in the number of sperm, egg production, blood feeding, and mating activity [84].

\subsection{Plants and their derivates}

For centuries, nature has created several active substances that, when applied correctly, can control insect pests such as mosquito in an efficient manner. The use of plants by man with insecticide purposes dates back to early human history. Due to their environmental advantages, the use of insecticides of vegetable origin in pest management has been increasing [85]. Among plants with potential activity against mosquitoes, Nim or Neem (Azadirachta indica) causes stunted growth, loss of appetite, reduction of fertility, molting disorders, morphological defects, and behavioral changes [86]. Moreover, it has been demonstrated that raw or partially purified plant extracts are most effective for mosquito control in place of the purified compounds or extracts [87]. The snuff (Nicotiana tabacum) is used, thanks to its insecticide and insect repellent action, where nicotine acts on the nervous system of insects through breathing, ingestion, and contact [88]. Other plants from which oils are extracted are garlic (Ocimum basilicum) and cinnamon (Cinnamomum osmophloeum), which have been shown to have 
insecticidal properties against larvae and adults of A. albopictus, Culex quinquefasciatus, and Armigeres subalbatus.

\subsection{Biological agents}

Among biological agents used for mosquito control can be mentioned derivatives of viruses, bacteria, and fungi. Entomopathogenic virus spreads from one insect generation to the next causing paralysis and eventually death on mosquito larvae being more effective in the first stage of development [89]. Within bacteria, only reports of Bacillus thuringiensis, B. sphericus, and B. popilliae with possibilities to exercise control over dipterans insects currently exist. These bacteria, during the sporulation process, produce protein crystals with insecticidal effect and/ or some toxins with the same effect [90]. Bacillus initially causes diarrhea and intestinal paralysis in mosquito, giving rise to a decrease of body movements, convulsions, and general paralysis. Internally, within the mosquito stomach, $B$. thuringiensis releases toxic crystals that paralyze the insect gut stopping peristalsis, causing that the insect stop feeding and die by starvation. Within the gut, bacteria multiply until they break the epithelium and invade the rest of the insect body. However, its use for mosquito control is scarce and presents some drawbacks as its duration in the environment is limited, its dispersion is rather inefficient, and the susceptibility to bacterial infection in the pest population is very heterogeneous. There are very sensitive individuals and other highly resistant. Fungi are other microorganisms that may be used to control mosquito vectors, of which 400 species are known with insecticide potential. About 20 of them have been given more attention, including those in the Lagenidium, Entomophaga, Neozygites, Entomophtora, Erynia, Aschersonia, Verticillium, Nomuraea, Hirsutella, Metarhizium, Beauveria, and Paecilomyces genera [91]. Although, entomopathogenic fungi are not as specific as bacteria or viruses, spores persist and infect insect successive generations, so that when the infection is established, its effects can last several years. Infection occurs by adhesion of the spores on the insect cuticle, where these germinate and penetrate the cuticle leading to insect colonization by mycelium. Cuticle penetration occurs through the use of an enzyme complex that the fungi use to feed. The entomopathogenic fungus most used in controlling mosquito infestations is Beauveria bassiana, which produces various active ingredients such as beauvericin [92].

The biological control of mosquito larvae with predators and other biological control agents could be a more effective and environmentally friendly strategy, thus avoiding the use of synthetic chemicals and the consequent environmental damage [93]. Among them, some insects and vertebrates such as fish, amphibians, and some mammals have the potential to control mosquito disease-vector populations. Within vertebrates, amphibians, bats, and fish have been used to control populations of mosquito. For example, using larvivorous fish species, control of mosquito larvae in deposits used to store water has been achieved [41]. Moreover, bats are responsible for capturing flying insects such as mosquitoes at night; similarly, toads and frogs consume large numbers of insects, slugs, worms, and other invertebrates [94]. However, the use of frogs and tadpoles for disease vector control is still largely unexplored. 


\section{Development of resistance to chemical insecticides}

Insecticide resistance is defined as the development of the ability of a insect population to tolerate doses of an insecticide, which would be lethal to the majority of individuals in a normal population of the same species and is also the result of pressure of positive selection exerted by the insecticide on the low frequency genes initially present in the vector insect [95]. Therefore, the development of resistance by mosquito disease vectors is of international concern due to the increase worldwide exchange of plant matter that mosquitoes can spread to other parts of the world, spreading resistance genes of the plagues that they have.

Most mosquito vector control programs of diseases in humans are mainly based on the use of chemical insecticides by outdoor spraying, impregnated nets, or indoor residual spraying [96]. Thereon, the use of insecticides has helped to eradicate insect-borne diseases. In this regard, since 1950, different classes of insecticides have been successively used. Organophosphates and pyrethroid insecticides have been used to control mosquito populations in their larval and adult stages. However, more recently, the disease vector control programs are based largely on the use of synthetic pyrethroid insecticides, which are recommended by the WHO only for impregnated nets [97]. However, the massive use of pesticides has caused detrimental effects on the agroecosystem, such as the acquisition of resistance, pest resurgence, and environmental pollution. Resistance has developed in more than 84 species of mosquitoes for each of the groups of toxicological insecticides [98]. Furthermore, it was found that insecticide residues accumulated in plants often end up in water bodies where mosquito larvae feeding on such plant debris or grow in water bodies enriched with plant compounds and interactions between these xenobiotics generate tolerance to insecticides or promote detoxification pathways of these insecticides against mosquitoes [99]. In addition to abiotic factors, biotic interactions that occur among mosquitoes, the pathogens that they transmit and their microbiome (microbes living in the mosquito) may also occur [96]. These vary from symbionts to entomopathogen opportunistic organisms that are able to affect various physiological host processes, such as detoxification systems [100] or the opposite effect leading to the appearance of insecticide resistance [101]. Furthermore, allelochemicals inducing enzyme production in insects can increase their tolerance to pesticides [102]. On the other hand, other studies have shown that the degree of development of a plant can affect insecticide resistance in insects [103].

There are two main mechanisms by which mosquito vectors can develop resistance to insecticides: alterations in the target site of action and metabolic resistance, also called increased rate of detoxification of insecticides [19]. Other less common mechanisms that develop resistance in insects are the resistance per behavior and the resistance per decreased penetration through the cuticle or cross resistance [104].

\subsection{Resistance mechanisms}

Each insecticide triggers the selection of one or more mechanisms of resistance; in addition, an unknown number of behavioral changes in adults. For instance, changes in the target site of action are produced when no silent mutations occur in structural genes that produce an alteration of amino acids responsible for anchoring the insecticide at a specific site. For 
example, resistance have been reported by altering the voltage-dependent sodium channel that is the target site of action for pyrethroids and organochlorines, such as DDT, and in the insensitive acetylcholinesterase, which is the target site of action for organophosphate and carbamate [19]. Furthermore, the metabolic detoxification is an acquired resistance mechanism, which is regulated by the activity of certain oxidized enzymes such as mixed function oxidase, esterases, glutathione S-transferases, and in specific cases DDTdehidroclorinase. Mixed function oxidase represents an important detoxification mechanism in the degradation of carbamates; moreover, esterases have an important role in the degradation of phosphorus insecticides [105]. Meanwhile, the metabolic resistance occurs through the increase in the detoxification of the insecticide. The most important form of metabolic resistance is given by detoxifying enzymes type glutathione S-transferase, mixed function oxidases, and esterases [78].

On the other hand, cross resistance can occur in two ways, positive and negative. The positive cross resistance refers to resistance to several insecticides due to expression in a single resistance mechanism [106]. Therefore, cross resistance occurs when a single gene confers resistance to a number of chemicals in the same group, such as $k d r$ gene conferring resistance to DDT and pyrethroids [95]. Meanwhile, negative cross resistance occurs due to an increase in susceptibility to the insecticide "A," caused by the development of resistance to insecticidal " $\mathrm{B}$ " and vice versa. For example, in Culex pipiens quinquefasciatus larvae, it was found that resistance to organophosphorus insecticides increases susceptibility to pyrethroid insecticides [107].

Furthermore, multiple resistances occur when two or more resistance mechanisms independently selected are operating in the same insect [19]. However, the term multiple resistances not necessarily involve the cross-resistance term because an insect may be resistant to two or more insecticides, and each resistance can be attributed to different mechanisms [78]. Consequently, each additional mechanism of resistance leads to a wide cross resistance, which restricts the number of possible alternatives for the control and in extreme conditions, leading to highly resistant populations to virtually all available insecticides [108].

\section{Conclusion}

Mosquito-borne diseases are influenced by biological, ecological, social, and economic factors. Unfortunately, in most cases, deaths occur in rural areas where medical care is inadequate because resources are limited. Some of the mosquito-borne disease symptoms are mild and easy to treat; however, for other disease, antiviral drugs and antibiotics are not effective for controlling the virus, and there is still no vaccine available for prevention. One of the strategies used as a preventive measure to control the spread of diseases is the elimination of mosquitoes and their breeding sites. The main strategy for the elimination of mosquitoes is the use of chemical insecticides. However, their control is complicated because the frequent use of chemical insecticides generates resistance and the insecticides decrease their effectiveness. The use of plants, fungi, and bacteria with potential activity have some beneficial effects for the environment, but its duration is limited and some mosquitoes develop high resistance. A 
promising alternative is the use of chemicals and natural insecticides intended to modify the normal functioning of the mosquitoes that transmit diseases and which do not affect the environment.

\section{Author details}

Jaime A. Cuervo-Parra ${ }^{1}$, Teresa Romero Cortés ${ }^{1}$ and Mario Ramirez-Lepe ${ }^{2^{*}}$

*Address all correspondence to: lepe@itver.edu.mx

1 Escuela Superior de Apan, Carretera Apan-Calpulalpan, Apan, México

2 Instituto Tecnológico de Veracruz, Unidad de Investigación y Desarrollo en Alimentos, Veracruz, México

\section{References}

[1] Knowtlon K, Solomon G, Rotkin-Ellman M. Fever Pitch, Mosquito-Borne Dengue Fever Threat Spreading in the Americas. NRDC Issue paper. 2009; 4-22.

[2] García-Gutiérrez C, Gómez-Peraza RL, López ACE, León-Váldez A. Insecticidas biorracionales para el control de mosquitos y moscas negras en Sinaloa. Ra Ximhai. 2012; 8: 47-55.

[3] Henao S, Pérez FJ. Manejo de plagas sin químicos: manual para docentes. 2nd ed. San José, Costa Rica. Radio Nederland Training Center, División Internacional. 2003; 3-80.

[4] Grandadam M, Caro V, Plumet S, Thiberge JM, Souarès Y, Failloux AB, Tolou HJ, Budelot M, Cosserat D, Leparc-Goffart I, Desprès P. Chikungunya virus, southeastern France. Emerging Infection Diseases. 2001; 17: 910-913.

[5] DCHP. Surveillance and Control of Selected Mosquito-Borne Diseases in Florida. Guidebook. Florida Health. 2014; 8-29.

[6] Almirón W, Crocco L. Mosquitos Urbanos Transmisores de Dengue y Encefalitis de San Luis, Manual de capacitación Docente. Editorial Científica Universitaria. Córdoba, Argentina. 2007; 14-51.

[7] Vargas HJ. Prevención y control de la Malaria y otras enfermedades transmitidas por vectores en el Perú. Revista Peruana de Epidemiología. 2003; 11: 1-18. 
[8] Boratne AV, Jayanthi V, Datta SS, Singh Z, Senthilvel V, Joice YS. Predictors of knowledge of selected mosquito-borne diseases among adults of selected peri-urban areas of Puducherry. Journal of Vector Borne. Diseases. 2010; 47: 249-256.

[9] Torrades S. La malaria y la controversia sobre su vacuna. OFFARM. 2001; p. 140-143.

[10] Secretaría de Salud de México (SSM). Programa de Acción: Enfermedades transmitidas por Vector. México, DF.

[11] Guerra CA, Gikandi PW, Tatem AJ, Noor AM, Smith DL, Hay SI, Snow RW. The limits and intensity of Plasmodium falciparum transmission: implications for malaria control and elimination worldwide. PLoS Medicine. 2008; 5: 300-311.

[12] Targett ATG, Moorthy SV, Brown GV. Malaria vaccine research and development: the role of the WHO MALVAC committee. Malaria Journal. 2013; 12: 362.

[13] Bisset LJA, Rodríguez MM, San Martín JL, Romero JE, Montoya R. Evaluación de la resistencia a insecticidas de una cepa de Aedes aegypti de El Salvador. Revista Panamericana de Salud Publica. 2009; 26: 229-234.

[14] GVCET (Grupo de Vigilancia y Control de Enfermedades Transmisibles). Protocolo de Vigilancia y Control de Fiebre Amarilla. Subdirección de Vigilancia y Control en Salud Pública. PRO-RO22.003.0000.009. 2010; 1-18.

[15] Barnett DE. Yellow fever: epidemiology and prevention. Clinical Infectious Diseases. 2007; 44: 850-856.

[16] AMSE (Asociación de Médicos de Sanidad Exterior). Fiebre Amarilla. Epidemiología y Situación Mundial. [Internet]. 2012. Available: http://www.amse.es/index.php?option=com_content\&view $=\quad$ article\&id=84:fiebre-amarilla-epidemiologia-y-situacionmundial\&catid=42:inf-epidemiologica\&Itemid=50 [Accessed: $2015 / 06 / 10]$.

[17] Staples JE, Gershman M, Fischer M. Yellow fever vaccine recommendations of the Advisory Committee on Immunization Practices (ACIP). Morbidity and Mortality Weekly Report. 2010; 59: 1-27.

[18] Gibbson RV, Vaughn DW. Dengue: an escalating problem. British Medical Journal. 2002; 324: 33-42.

[19] Maestre SR, Gómez CD. Dengue: Epidemiología, políticas públicas y resistencia de vectores a insecticidas. Revista Ciencias Biomedicas. 2013; 4: 302-317.

[20] de la Monte S, Castro F, Bonilla NJ, Gaskin de UA, Hutchins GM. The systemic pathology of Venezuelan equine encephalitis virus infection in humans. American Journal of Tropical Medicine and Hygiene. 1985; 34: 194-202.

[21] Brown DT, Condreay LD. Replication of alphaviruses in mosquito cells. In: Schlesinger S, Schlesinger MJ, editors. The Togaviridae and Flaviviridae. Plenum Press, New York; 2003. p. 171-207. 
[22] Zacks MA, Paessler S. Encephalitic alphaviruses. Veterinary Microbiology. 2010; 140: 281-286.

[23] Sidwell RW, Gebhardt LP, Thorpe BD. Epidemiological aspects of venezuelan equine encephalitis virus infections. Bacteriological Reviews. 1967; 31: 65-81.

[24] Estrada-Franco JG, Navarro-Lopez R, Freier JE, Cordova D, Clements T, Moncayo A, Kang W, Gomez-Hernandez C, Rodriguez-Dominguez G, Ludwig GV, Weaver SC. Venezuelan equine encephalitis virus, Southern Mexico. Emerging Infectious Diseases. 2004; 10: 2113-2121.

[25] Knipe DM, Howley PM. Fields Virology. 6th ed. Lippincot Williams \& Wilkins, Philadelphia; 2003. p. 2456.

[26] Hemmerter S, Slapeta J, van den Hurk AF, Cooper DR, Whelan IP, Russell CR, Johansen AC, Beebe WN. A curious coincidence: mosquito biodiversity and the limits of the Japanese encephalitis virus in Australasia. BMC Evolutionary Biology. 2007; 7: 1-11.

[27] OIE-Organización Mundial de Sanidad Animal. Encefalitis Japonesa. In: Manual de la OIE sobre animales terrestres. Organización Mundial de Sanidad Animal. 2010; p. 1-9.

[28] Tsai TF. Factors in the changing epidemiology of Japanese encephalitis and West Nile fever. In: Saluzzo JF, editor. Factors in the Emergence of Arboviral Diseases. Elsevier Amsterdam; 1997. p. 179-189.

[29] Malaria. Mundi. Otras Enfermedades Infecciosas, Encefalitis Japonesa. [Internet]. 2014. Available: http://malariamundi.com/otras-enfermedades-infecciosas/encefalitisjaponesa [Accessed: 2015/05/25].

[30] Díaz-Menéndez M, Norman F, Monge-Maillo B, Pérez-Molina JA, López-Vélez R. Enfermedades Infecciosas y Microbiología Clínica. Enfermedades Infecciosas y Microbiologia Clinica. 2011; 29: 27-37.

[31] Hotez PJ, Molyneux DH, Fenwick A, Kumaresan J, Sachs SE, Sachs JD, Sachs JD, Savioli MDL. Control of neglected tropical diseases. New England Journal of Medicine. 2007; 357: 1018-1027.

[32] Global Programme to Eliminate Lymphatic Filariasis (GPELF). Progress Report 20002009 and Strategic Plan 2010-2020. Geneva, World Health Organization. 2010; p. 78.

[33] OIE - World Organisation for Animal Health. Rift Valley Fever. OIE Terrestrial Manual 2014. OIE Reference Laboratories. 2014; p. 1-20.

[34] European Food Safety Authority (EFSA). EFSA Panel on Animal Health and Welfare (AHAW); Scientific Opinion on Rift Valley fever. EFSA Journal. 2013; 11: 1-48.

[35] Center for Food Security and Public Health (CFSPH). Rift Valley Fever. Institute for International Cooperation in Animal Biologics. Iowa State University. 2006; p. 1-5. 
[36] Ikegami T. Molecular biology and genetic diversity of Rift Valley fever virus. Antiviral Research. 2012; 95: 293-310.

[37] Granwehr BP, Lillibridge KM, Higgs S, Mason PW, Aronson JF, Campbell GA, Barrett AD. West Nile virus: where are we now? Lancet Infectious Diseases. 2004; 4: 547556.

[38] Weingartl HM, Neufeld JL, Copps J, Marszal P. Experimental West Nile virus infection in blue jays (Cyanocitta cristata) and crows (Corvus brachyrhynchos). Veterinary Pathology. 2004; 41: 362-370.

[39] Snook CS, Hymann SS, Del Piero F, Palmer JE, Ostlund EN, Barr BS, Deroschers AM, Reilly LK. West Nile virus encephalomyelitis in eight horses. Journal of the American Veterinary Medical Association. 2001; 218: 1576-1579.

[40] OIE-World Organisation for Animal Health. West Nile Fever. OIE Terrestrial Manual 2013. OIE Reference Laboratories. 2013; p. 1-12.

[41] Connelly CR, Bolles E, Culber D, De Valerio J, Donahoe M, Gabel K, Jordi R, McLaughlin J, Neal A, Scalera S, Toro E, Walter J. Florida Resident's Guide to Mosquito Control, Integrated Pest management for Mosquito Reduction around Homes and Neighborhoods. University of Florida, USDA-NIFA. 2014; p. 22-37.

[42] Frías-Salcedo JA. Actualización de aspectos clínicos epidemiológicos de la fiebre Chikungunya 2014. Revista de Sanidad Militar. 2014; 68: 313-317.

[43] Porta L. Fiebre Chikungunya Amenaza para la Región de las Américas. Salud Militar. 2012; 31: 25-33.

[44] Puente S, Rivas GP, Ramírez G, de Ory F, Lago M, Herrero MD, González LJ, Sánchez-Seco MP. Infección por virus de Chikungunya: 11 casos importados. In: VI Congreso de la Sociedad Española de Medicina Tropical y Salud Internacional. 5-7 Marzo 2008. Segovia, España.

[45] Rodrigues SG, Nunes MRT, Casseb SMM, Prazeres ASC, Rodrigues DSG, Silva MO, Cruz ACR, Tavares-Neto JC, Vasconcelos PFC. Molecular epidemiology of Saint Louis encephalitis virus in the Brazilian Amazon: genetic divergence and dispersal. Journal of General Virology. 2010; 91: 2420-2427.

[46] Reisen WK. Epidemiology of St. Louis encephalitis virus. In: Maramorosch K, Murphy FA, Shatkin AJ, editors. Advances in Virus Research. Elsevier. San Diego; 2003. p. 139-183.

[47] New York State Department of Health (NYSDOH). Mosquito Borne Illness Surveillance \& Response Plan 2012. 2012; p. 4-5.

[48] Farber S, Hill A, Connerly ML, Dingle JH. Encephalitis in infants and children caused by the virus of the eastern variety of equine encephalitis. JAMA. 1940; 114: 17251731. 
[49] Piliero PJ, Brody J, Zamani A, Deresiewicz RL. Eastern equine encephalitis presenting as focal neuroradiographic abnormalities: case report and review. Clinical Infectious Diseases. 1994; 18: 985-988.

[50] Monath TP. Arthropod-borne encephalitides in the Americas. Bulletin World Health Organization. 1979. 57: 513-533.

[51] Ray CG. Arthropod-borne and other zoonotic viruses. In: Ryan KJ, Ray CG, editors. Sherris Medical Microbiology. 4th ed. McGraw-Hill. New York. 2004; p. 585-596.

[52] OIE-World Organisation for Animal Health. Equine Encephalomyelitis (Eastern and Western). OIE Terrestrial Manual 2013. OIE Reference Laboratories. 2013; p. 1-9.

[53] Mahmood F, Reisen WK, Chiles RE, Fang Y. Western equine encephalomyelitis virus infection affects the life table characteristics of Culex tarsalis (Diptera: Culicidae). Journal of Medical Entomology. 2004; 41: 982-986.

[54] Walton TE. Venezuelan, eastern, and western encephalomyelitis. In: Gibbs EPJ, editor. Virus Diseases of Food Animals. A World Geography of Epidemiology and Control. Disease Monographs. Vol. 2. Academic Press, New York. 1981. p. 587-625.

[55] Minnesota Department of Health (MDH). Western Equine Encephalitis Fact Sheet. Minnesota Department of Health. 2006; p. 1.

[56] Ohio Department of Health (ODH). La Crosse Virus Disease. Ohio Disease Reporting System. 2015; p. 1-9.

[57] Rey JR. La Crosse Encephalitis. University of Florida. IFAS Extension. 2002; p. 1-2.

[58] Calisher CH. Medically important arboviruses of the United States and Canada. Clinical Microbiology Reviews. 1994; 7: 89-116.

[59] Moore CG, McLean RG, Mitchell CJ, Nasci RS, Tsai TF, Calisher CH, Marfin AA, Moore PS, Gubler DJ. Guidelines for Arbovirus Surveillance in the United States. Center of Disease Control, U.S. Department of Health and Human Services, Fort Collins, Colorado.1993; p. 14-16.

[60] Akoua-Koffi C, Diarrassouba S, Bénié VB, Ngbichi JM, Bozoua T, Bosson A, Akran V, Carnevale P, Ehouman A. Investigation surrounding a fatal case of yellow fever in Côte d'Ivoire in 1999. Bulletin de la Societe Pathologie Exotique. 2001; 94: 227-230.

[61] Centre for Disease Control (CDC). Zika Virus Infection. Northern Territory Government. Australia. 2014; p. 1-2.

[62] Hayes EB. Zika Virus Outside Africa. Emerging Infectious Diseases. 2009; 15: 13471350.

[63] Fathy KH. Ecosmart biorational insecticides: alternative insect control strategies. In: Perveen F, editor. Insecticides - Advances in Integrated Pest Management. InTech. Rijeka; 2012. p. 17-60. 
[64] Koul O, Walia S, Dhaliwal GS. Essential oils as green pesticides: potential and constraints. Biopesticide International. 2008; 4: 63-84.

[65] Díez DM. Efecto del Metopreno sobre la metamosfosis de la cucaracha, Blattella germanica [thesis]. Vizcaya: Universidad del País Vasco. 2013.

[66] Mamatha DM, Kanji VK, Cohly H, Rajeswara RM. Juvenile hormone analogues, methoprene and fenoxycarb dose dependently enhance certain enzyme activities in the silkworm Bombyx mori (L). International Journal of Environmental Research Public Health. 2008; 5: 120-124.

[67] Ware GW, Whitacre DM. Introducción a los Insecticidas. The Pesticide Book, 6th ed.. Willoughby; 2004.

[68] Rey VG. Determinación de los grados de resistencia al insecticida temefos en poblaciones de Aedes aegypti Linnaeus 1762, (Diptera: Culicidae) y su implicación en la eficacia del insecticida en los departamentos de Cauca, la Guajira, Cundinamarca y Atlántico.] Díez DM. Efecto del Metopreno sobre la metamosfosis de la cucaracha, Blattella germanica. [thesis]. Bogotá: Universidad Nacional de Colombia. 2011.

[69] Mazzacano C, Hoffman BS. Ecologically Sound Mosquito Management in Wetlands. The Xerces Society for Invertebrate Conservation. 2013; p. 2-10.

[70] Fortin CA, Maire A, Leclair R. The residual effect of temephos (Abate 4-E) on nontarget communities. Journal of the American Mosquito Control Association. 1987; 3: 282-288.

[71] USFWS. Appendix K4. Environmental Effects of Mosquito Control. 2004; p. 1-20.

[72] Gile S, Johns A, Thai V. Integrated Pest Management for Mosquito Control in Massachusetts [thesis]. Massachusetts: Worcester Polytechnic Institute. 2013.

[73] Reigart RJ, Roberts JR. Recognition and Management of Pesticide Poisonings. 5th ed. U.S. Environmental Protection Agency: Washington, DC. 1999; p. 34-93.

[74] Brown AE. Mode of action of insecticides and related pest control chemicals for production agriculture, ornamentals, and turf. Pesticide Information Leaflet. 2006; 43: 113.

[75] Reigart RJ, Roberts JR. Recognition and Management of Pesticide Poisonings. 5th ed. U.S. Environmental Protection Agency: Washington, DC. 1999; p. 34-93.

[76] Pan American Health Organization (PAHO). Integrated Vector Management (IVM). [Internet]. 2011. Available: http://www.paho.org/English/AD/DPC/CD/ivm.htm [Accessed 2015/05/18].

[77] Woodard V, Meléndez JL. Preliminary environmental fate and effects assessment science chapter for the registration eligibility decision of D-Phenothrin (Sumithrin)®. U.S. Environmental Protection Agency. ID: EPA-HQ-OPP-2008-0140-0005. 2008; p. 716. 
[78] Bisset J. Uso Correcto de Insecticidas: Control de la resistencia. Revista Cubana de Medicina Tropical. 2002; 54: 202-219.

[79] Guglielmone A, Castelli M, Volpogni M, Medus P, Anziani O, Mangold A. Comparación de la concentración letal 50 de diazinón y cipermetrina para Haematobia irritans (Diptera: Muscidae) entre áreas de producción de leche o carne de Santa Fe y Entre Ríos, Argentina. Revista de Medicina Veterinaria. 2001; 82: 209-211.

[80] Environmental Protection Agency (EPA). Permethrin. United States Environmental Protection Agency, Prevention, pesticides and Toxic Substances, EPA 738-F-09-110. 2009; p. 11.

[81] Klowden MJ, Chambers GM. Ovarian development and adult mortality in Aedes aegypti treated with sucrose, juvenile hormone and methoprene. Journal of Insect Physiology. 1989; 35: 513-517.

[82] Kawada H. New mosquito control techniques as countermeasures against insecticide resistance. In: Perveen F, editor. Insecticides. Advances in Integrated Pest Management. InTech; 2012. p. 657-682.

[83] Williams CR, Leach KJ, Wilson NJ, Swart VR. The allee effect in site choice behavior of egg-laying dengue vector mosquitoes. Tropical Biomedicine. 2008; 25: 140-144.

[84] Iwanaga K, Kanda T. The effects of a juvenile hormone active oxime ether compound on the metamorphosis and reproduction of an Anopheline vector, Anopheles balabacensis. Applied Entomology and Zoology. 1988; 23: 186-193

[85] Leyva M, Marquetti MdelC, French L, Montada D, Tiomno O, Tacoronte JE. Efecto de un aceite de trementina obtenido de Pinus tropicalis Morelet sobre la biología de una cepa de Aedes (Stegomyia) aegypti Linnaeus, 1762 resistente a insecticidas. Anales de Biología. 2013; 35: 75-84.

[86] Wandscheer CB, Duque JE, da Silva MAN, Fukuyama Y, Wohlke JL, Adelmann J, Fontana JD. Larvicidal action of ethanolic extracts from fruit endocarps of Melia azedarach and Azadirachta indica against the dengue mosquito Aedes aegypti. Toxicon. 2004; 44: 829-835.

[87] Abdelouaheb A, Nassima R, Noureddine S. Larvicidal activity of a neem tree extract (Azadirachtin) against mosquito larvae in the Republic of Algeria. Biological Sciences. 2009; 2: 15-22.

[88] Brechelt A. Manejo Ecológico de Plagas y Enfermedades. Red de Acción en Plagicidas y sus Alternativas para América Latina (RAP-AL). Santiago de Chile, Chile. 2004; p. 4-35.

[89] Primo YE. Mundi prensa ed. Ecología química. Nuevos métodos de lucha contra insectos. Madrid; 1991. p. 191. 
[90] Badii MH, Abreu JL. Control biológico una forma sustentable de control de plagas. Daena: International Journal of Good Conscience. 2006; 1: 82-89.

[91] Van Driesche RG, Bollows TS. Biological Control. Chapman \& Hall. New York; 1996. p. 539.

[92] García GC, Tamez GP. Mercado de bioinsecticidas en México. Curso de agricultura orgánica y sustentable. Fundación Produce Sinaloa. 2012; p. 99-114.

[93] Kumar R, Hwang JS. Larvicidal Efficiency of Aquatic Predators: A Perspective for Mosquito Biocontrol. Zoological Studies. 2006; 45: 447-466.

[94] Mahr LD, Whitaker P, Ridgway N. Biological control of insects and mites: an introduction to beneficial natural enemies and their use in pest management, UW Extension, Wisconsin Madison. 2008; p. 58.

[95] World Health Organization (WHO). Seventh report Expert Committee on insecticides WHO Tech Report Ser. 1957; 125: 37.

[96] Nkya TE, Akhouayri I, Kisinza W, David JP. Impact of environment on mosquito response to pyrethroid insecticides: facts, evidences and prospects. Insect Biochemistry and Molecular Biology. 2013; 43: 407-416.

[97] World Health Organization (WHO). Malaria Vector Control and Personal Protection. Report of the World Health Organization. 2006; p. 1-61.

[98] Falero GC. Pruebas de susceptibilidad de mosquito adulto y larvas a los insecticidas y bioensayos de las aplicaciones residuales usadas en el control de mosquitos vectores de malaria y dengue. 2001; p. 2-47.

[99] David JP, Boyer S, Mesneau A, Ball A, Ranson H, Dauphin-Villemant C. Involvement of cytochrome P450 monooxygenases in the response of mosquito larvae to dietary plant xenobiotics. Insect Biochemistry and Molecular Biology. 2006; 36: 410-420.

[100] Behura SK, Gomez-Machorro C, Harker BW, de Bruyn B, Lovin DD, Hemme RR, Mori A, Romero-Severson J, Severson DW. Global cross-talk of genes of the mosquito Aedes aegypti in response to dengue virus infection. PLoS Neglected Tropical Diseases. $2011 ; 5: 1-13$.

[101] Kikuchi Y, Hayatsu M, Hosokawa T, Nagayama A, Tago K, Fukatsu T. Symbiontmediated insecticide resistance. Proceedings of National Academy Sciences. 2012; 109: 8618-8622.

[102] Brewer MJ, Meade T, Trumble JT. Development of insecticide-resistant and susceptible Spodoptera exigua (Lepidoptera: Noctuidae) exposed to furanocoumarins found in celery. Environmental Entomology. 1995; 24: 392-401.

[103] Attah PK, van Emden HF. The susceptibility to malathion of Metopolophium dirhodum on 2 wheat species at 2 growth stages, and the effect of plant growth regulators on this susceptibility. Insect Science and its Application. 1993; 14: 101-106. 
[104] Fonseca I, Quiñones M. Resistencia a insecticidas en mosquitos (Diptera: Culicidae): mecanismos, detección y vigilancia en salud pública. Revista Colombiana de Entomologia. 2005; 31: 107-115.

[105] Sosa MA. Consideraciones generales sobre resistencia de los insectos a los plaguicidas con especial referencia a los "piretroides." Publicación Miscelánea. N5. INTA Reconquista. 1992; p. 5-10.

[106] Mani GS. Evolution of resistance in the presence of two insecticides. Genetics. 1985; 109: 761-783.

[107] Lagunes TA. Impact of the use of mixtures and sequences of insecticides in the evolution of resistance in Culex quinquefasciatus Say (Diptera: Culicidae) [thesis]. Riverside California: University of California. 1980.

[108] Keiding J. Resistance in the housefly in Denmark and elsewhere. In: DL Watson, editor. Pesticide management and insecticide resistance. New York: Academic Press; 1977. p. 261-302. 